\title{
Arte Juntos/Art Together: Promoting School Readiness among Latino Children through Parent Engagement and Social Inclusion in a Suburban Museum
}

\author{
*Zoila Tazi, **Helena Vidal, ${ }^{* * * K a r e n ~ S t e i n ~}$
}

\begin{abstract}
Census data reveal that suburban communities are becoming increasingly diverse. Once considered affluent and predictable places, American suburbs are now confronting increasing poverty rates as well as ethnic, racial and linguistic diversity. Currently, more than half of US Latinos live in the suburbs. Schools and public institutions such as museums are challenged to provide programming that meets the needs of Latinos, who are disproportionately poor (Ackerman and Tazi 2015:3). Promoting school readiness among Latino children is an important effort in maximizing the potential and educational attainment of this growing population.

In one suburban community, a school-museum collaboration resulted in a bilingual parent-child program promoting school readiness and social inclusion for Latino families. Arte Juntos/Art Together engaged parents and children using art and culture-based activities that developed observation skills, creativity, critical thinking, vocabulary, and aesthetic appreciation. Celebrating diverse perspectives and self-expression, the program provided access to museums as enriching spaces for informal learning, personal empowerment and social inclusion.
\end{abstract}

Key Words: early childhood, parent-child interactive learning, bilingual, Latino, immigrant families, social inclusion, informal learning in museums, Visual Thinking Strategies

\section{Introduction}

Suburban communities across the United States are becoming increasingly diverse. Analyses of the 2010 census data highlight how American suburbs, traditionally considered enclaves for more affluent, homogeneous populations, are now 'at the forefront of the country's ongoing demographic transformation' in terms of the racial, ethnic, cultural, socio-economic, and linguistic make up of their populations (Berube 2011:1). Ethnic and linguistic diversity is largely driven by the increase in Hispanic/Latino ${ }^{1}$ households, where three out of four young Latino children live in homes where Spanish is spoken regularly (García and Jensen 2009: 23), and where the poverty rates are among the highest in the country (Children's Defense Fund 2011: 41). Currently, 54 per cent of Latinos in America live in the suburbs (Suro and Singer 2002: 1).

In response to a change in demographics, communities are challenged to adopt culturally and linguistically competent approaches to organize public systems. For suburban museums, adopting ideals of social inclusion enhances the possibilities to engage a broad, diverse audience with meaningful art experiences. However, marginalized and poor communities, such as immigrants, are difficult for museums to reach with traditional marketing efforts. Partnerships with public schools with growing immigrant populations can be instrumental in creating more responsive and culturally relevant programming that effectively reaches immigrant children and families. These partnerships also represent opportunities for the schools to gain support for academic achievement from the enrichment and unique nature of learning available in museums. Arte Juntos/Art Together was the result of a museum-school 
collaboration which brought Spanish-speaking immigrant families into a suburban museum with the goal of enhancing the children's school readiness by emphasizing museum literacy for parents and early learning experiences for their children. The program is an example of how museums can contribute to delivering equitable learning opportunities for immigrant children and their families, and build bridges towards social inclusion. It promotes a view of museums as community-builders and agents of change for a sustainable future (Sandell 2003: 49) in increasingly diverse communities.

\section{Social Inclusion}

Recent reports from the American Alliance of Museums' Center for the Future of Museums demonstrate the critical need for museums to become more accessible to diverse audiences. Museum audiences today are disproportionately comprised of non-Hispanic whites (78.9 per cent) compared to the significantly lower number of Hispanic (8.6 per cent) and African American (5.9 per cent) visitors (Farrell and Medvedeva 2010: 12). Given increasing demographic shifts, museums struggle to find effective ways to engage minority audiences today in order to remain sustainable and relevant. Visiting museums as a child remains a strong predictor of museum attendance as an adult; museums must be forward-looking by developing resources and programs that are accessible for diverse families with young children (Farrell and Medvedeva 2010: 14).

The ideals of social inclusion in museums extend beyond audience development or strategies to increase attendance. Instead, social inclusion seeks to interrupt the disenfranchisement inherent in economic disadvantage, discrimination and inequality in society (Sandell 2003: 46). As cultural institutions, museums can influence public discourse when they highlight the diverse, non-dominant, perspectives and experiences of the everyday world rather than promote an elitist view of art or art appreciation (Fernández-Cao, et al. 2010: 398; Sandell, 2002: 8). There is growing evidence that museums can contribute to more equitable societies through their programs (Sandell, 2012: 3) and that audiences can reap social and emotional benefits from their participation (Silverman 2002: 69). Sandell describes three realms influenced by social inclusion in museums: the individual, the community, and the society (Sandell 2002:4; 2003:45). Personal empowerment and increased creativity for the individual can enhance social engagement in their community; using exhibits to engender appreciation for the diverse talents and expression of all members of society promotes the tolerance and respect necessary for a productive multicultural society.

\section{School Readiness}

Within the context of changing demographics, there is also increased interest in universal early childhood education to equalize educational trajectories in diverse populations. Helping young children become better prepared for school is becoming recognized (Neuman and Bennett 2001: 246-54; Neuman 2003: 284-91; Magnuson et al. 2005: 169-96) as a means of preventing diminished outcomes in education. In addition, advances in neuroscience validate the need for enriching experiences in early childhood; community museums can play a critical role in providing these experiences for families with young children (Bowers 2012: 39-48).

Children enter schools with varying backgrounds, needs, abilities and resources which mirror the experiences in their first years of life before school. While school readiness has been defined in terms of interconnected developmental domains, recently the concept has become most associated with those skills and competencies linked to success in school (Snow 2007: 197). The standards movement in the United States may be driving the emerging definitions of school readiness; historically, early childhood teachers have rated maturity and social skills as significant indicators of school readiness, but recent studies of teacher expectations note the increased attention to pre-academic skills, particularly for children living in poverty (Snow 2007: 198).

Poverty is strongly associated with decreased school readiness (Janus and Duku, 2007: 395); Latino children are among the poorest in the country, but also experience other adverse conditions such as decreased rates of preschool enrollment, underemployment for 
the adults in the family, and limited parental education (Ackerman and Tazi, 2015:3-6). These conditions contribute to the trend of decreased school readiness among Latinos (Magnuson and Waldfogel 2005: 169-95). National studies of preschool children reveal gaps in early reading and math skills for Latinos even as they enter Kindergarten (Flanagan and McPhee 2009:9). Poor children, however, also attend the lowest quality schools (Lee and Burkham 2002:2) who may not be 'ready' to meet students' needs; under-resourced and ill-prepared, impoverished schools may in fact perpetuate social exclusion in some communities.

For any socioeconomic group, parents are the first to influence a child's early preparation for school. Consequently, efforts to enhance school readiness across diverse populations of young children target parent behaviors with their young children by promoting activities that engage the entire family (Swick 2009: 403-6). In this regard, school readiness can be directly impacted by the enriching informal learning experiences made available through museum programs designed for children and their parents. Falk and Dierking propose that museum programs and exhibitions that are designed for collaborative learning, where questions and dialogue are encouraged, support families as 'communities of learners.' Parents can be most effective as facilitators when they feel comfortable with the content and the museum environment (Falk and Dierking 2000: 94-95). Museums can support intergenerational activities, often preferred by immigrant families, by providing bilingual interpretive materials and other resources that help parents feel confident with the content as they guide their children's experiences, which leads to social inclusion (Stein, Garibay and Wilson 2008: 186-7). This article presents one example of a school-museum collaboration designed to support parents and enhance school readiness for young children in a diverse suburban community.

\section{One Community}

One community, pseudonymously called 'Rivertown,' is increasingly diverse in terms of race, ethnicity, socio-economic class, and language (Tazi 2010: 174-80). Despite enjoying a median income higher than the national average, Rivertown experienced a sharp increase in the number of children living in poverty entering the schools. Immigrant families, with limited English proficiency, are a growing constituency for Rivertown. The school district of Rivertown sought to proactively address disparities in school readiness with the creation of a unique bilingual family literacy program, entitled First Steps/Primeros Pasos (FS/PP). Conceived to attract any family in Rivertown with young children, the program design was predicated on two principles: programming would promote 'enrichment, not remediation' - rather than signal any deficiency in any group of children, the program sought to offer the enrichment all young children need before school; all services would be provided bilingually, in English and Spanish, in order to engage the growing population of Latino immigrants.

The opportunity for FS/PP to collaborate with a museum arose from the creative outreach and programming of a local community museum, the Katonah Museum of Art (KMA). Sandell's statement that 'much of the impetus for the development of projects aimed at social inclusion has come out of education and outreach' (Sandell 2003:48) was evidenced in the concept for a new program at the KMA. In response to the changing demographics of the larger suburban community, and with a desire to become more accessible and inclusive, the KMA, a non-collecting institution based in lower New York State, developed Arte Juntos/Art Together, a family literacy program targeting parents with pre-school aged children. In order to have an impact on the community, the KMA began to work in partnership with FS/PP in 2007 to learn more about the needs and wants of the Latino families in Rivertown, and how the museum could become an asset for the community.

\section{Arte Juntos/Art Together}

Arte Juntos/Art Together (AJ/AT) was designed as a bilingual art- and culture-based family literacy curriculum that introduced preschool Latino children and their families to the KMA as a resource for informal learning. Every academic year, beginning in 2007, approximately 60 families from the First Steps/Primeros Pasos participated in the AJ/AT program. The program ran from October to May with nine sessions in the fall semester and another nine sessions in the spring. The program's in-depth, multi-year, collaborative approach offered the partners 
opportunities for learning about the needs and assets of children, parents, and teachers, and how to best position the museum to support them as an effective and accessible learning resource, within the larger community learning landscape.

AJ/AT had two overriding goals: to promote the children's school readiness and to reinforce social inclusion among Latinos through parent engagement and access to informal learning experiences in museums. Using works of art in the KMA's exhibitions to develop the curriculum, AJ/AT supported the children's emergent literacy, observation skills, expressive and receptive language, and critical thinking skills. Through inquiry-based discussions using original art and picture book illustrations, and related art-making activities, children developed the ability to identify shapes, colors, and objects, expanded their vocabularies, and developed their fine motor skills. The children made multiple visits to the museum, which studies have found 'not only provides preschool students with opportunities to create personal connections to the museum, but also reinforces classroom learning, fosters new skills, and encourages fun' (Wickens 2012:92).

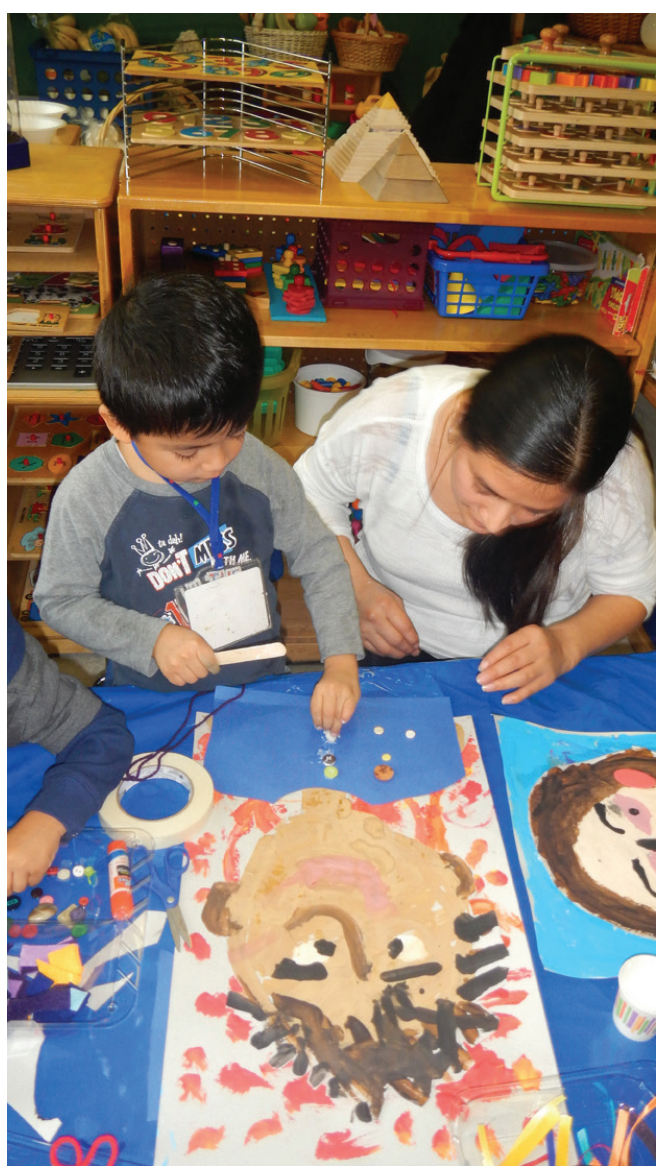

Fig 1. Parents support their children in the classroom and at the museum, using a variety of art materials and techniques. learned about early childhood curricular themes, developmentally appropriate teaching strategies, and information about the needs/wants of the community served. This collaborative process echoed Silverman's call for 'mutual mentorship and concentrated exchange of professional
With the aim of empowering parents to become resourceful facilitators of their children's learning, AJ/AT's innovative design included parents as participants who worked side by side with their children in the classroom, as well as in the museum. AJ/ AT educators reinforced the importance of conversation and play as the primary forms of learning during the preschool years, and demonstrated activities to "connect the dots between play and the skills needed for academic success' (Downey, Krantz, and Skidmore 2010:27). Parents were introduced to strategies to engage their child in informal learning experiences that build their capacity for becoming effective intermediaries for their children's success (Luke and McCreedy 2010: 5, Falk \& Dierking, 2002: 94-95). This is particularly important for low-income and immigrant families, for whom involvement in their children's education is often challenged by obstacles including work commitments, language, uncertainty about their role (Peña 2000), and their previous experiences with learning and formal education (Stein, Garibay and Wilson 2008: 187-88).

Designing the curriculum involved collaborative planning between the KMA staff and the FS/PP program staff, which included classroom educators, family literacy caseworkers, and adult English as a Second Language (ESL) instructors. Bi-annual retreats, which included time for planning, professional development, sharing of best practices, and assessment, were essential components of the program's success. The FS/PP team was introduced to the museum's culture and its inquiry-based teaching methodologies, while museum educators
elopmentally appropriate teaching strategies, 
expertise' which provides the best foundation for the museum's success as an effective agent for social change and social inclusion. (Silverman 2002: 70). Ongoing curriculum development, weekly debriefings after each session, and assessment meetings were integral to the program design, and helped educators build upon children's classroom experiences and knowledge (Wickens 2012: 94).

\section{Shared Strategy -- Supporting Vocabulary Development}

Robust language development is a strong indicator of school readiness, yet there is a link to poverty here as well. Language studies have documented vast differences between socioeconomic groups in the numbers of words young children know and use (Hart \& Risley 1995). Vocabulary is a strong predictor of achievement in early reading skills (Biemiller 2006: 41-51), and so early childhood educators encourage parents to read and converse with their children as essential early childhood experiences. Supporting vocabulary development was a shared strategy in the collaboration between the school and the museum, as it would advance both school readiness and visual literacy.

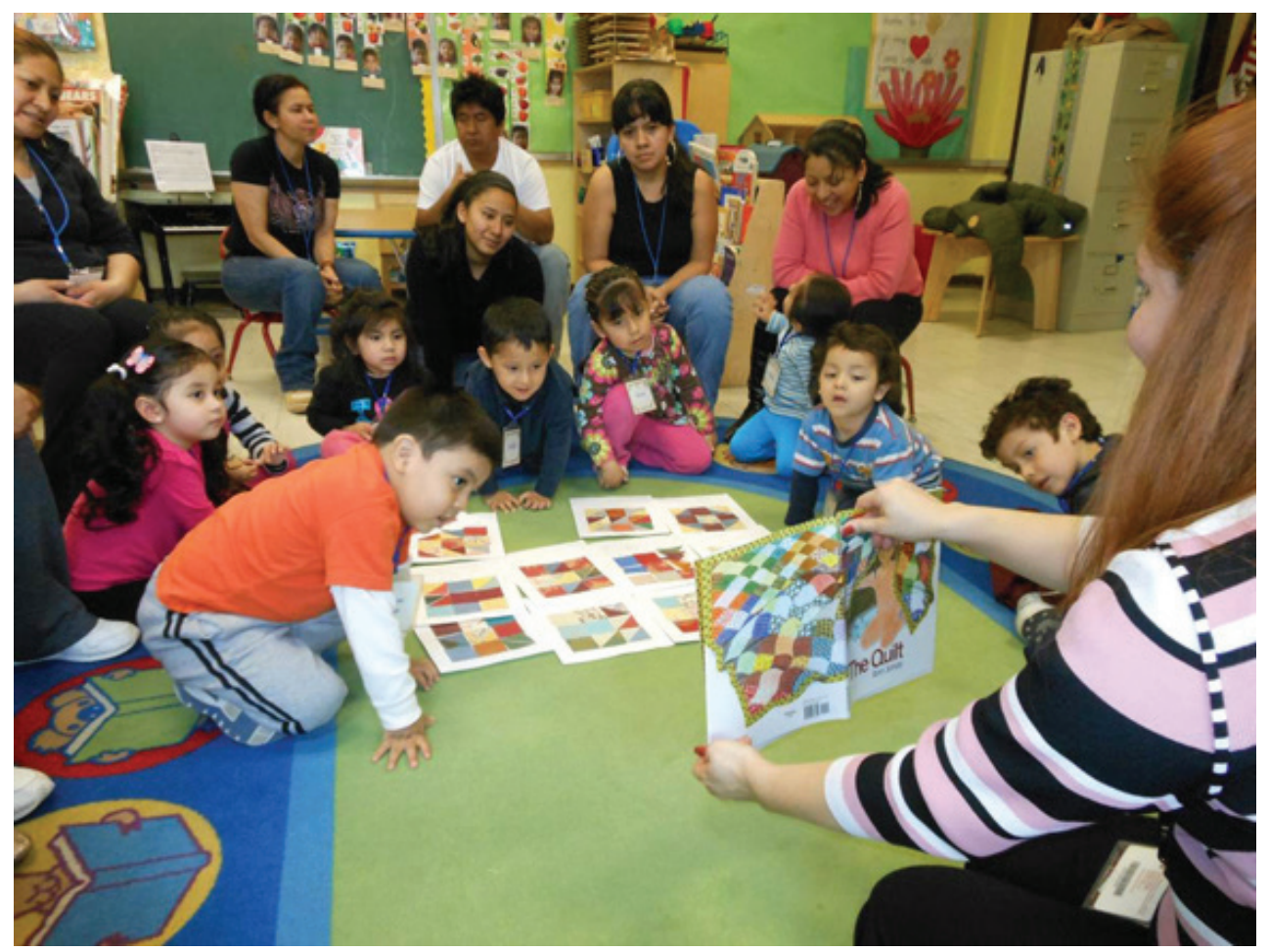

Fig 2. Reading picture books, combined with open-ended inquiry enriches the children's interpretations of the illustrations and their understanding of the story being read.

Engaging young children through encounters with original art in museums and illustrations in picture books supports and enriches their vocabulary and visual literacy skills - the unfolding ability to independently derive information and meaning from art and products of visual culture. Facilitated explorations of works of art and objects using open-ended inquiry with young children may involve finding and naming shapes and colors they see or sharing their interpretation of the narrative. It is in this area of visual literacy, within an environment that encourages authentic discovery and shared conversation, that early childhood education and museum education practices are richly aligned. 
One of the approaches employed by AJ/AT with children and parents was Visual Thinking Strategies (VTS), a methodology and curriculum developed by Abigail Housen and Philip Yenawine (2000), based on Housen's theory of aesthetic development (Housen 1983). Used in classrooms as well as museums, the VTS curriculum has been field tested since 1991; studies suggest that VTS builds critical thinking skills that transfer to content areas such as writing, mathematics, social studies, and science (Housen 2001). In addition, VTS is linked to academic growth in students with limited English skills ${ }^{2}$. The aim of VTS is not to teach about art, but to develop thinking skills by eliciting verbal responses based on the observation of carefully selected art images. It does so by employing three key questions (Housen 2001: 99-131):

1) What is going on in this picture?

2) What do you see that makes you say that?

3) What more can you find?

As facilitators of the exploration, museum or classroom educators use these open-ended questions to encourage observation and interpretation in group discussions. Facilitators paraphrase student responses, request visual evidence, link ideas, reinforce new vocabulary and provide neutral responses to student comments. While the VTS methodology is commonly used with K-12 students, recent work within a Montessori school highlights its effectiveness for enhancing emergent literacy skills in preschool children; VTS discussions were found to create opportunities to introduce new vocabulary through paraphrasing, and that these 'oral skills, bolstered by detailed observation, feed literacy development' (Whitescarver and Cossentino 2011: 20-1). AJ/AT facilitators used VTS and other inquiry based methodologies to encourage children aged three to four, and their parents, to look for details, develop their expressive and receptive language skills, and explore an image for more sustained periods of time.

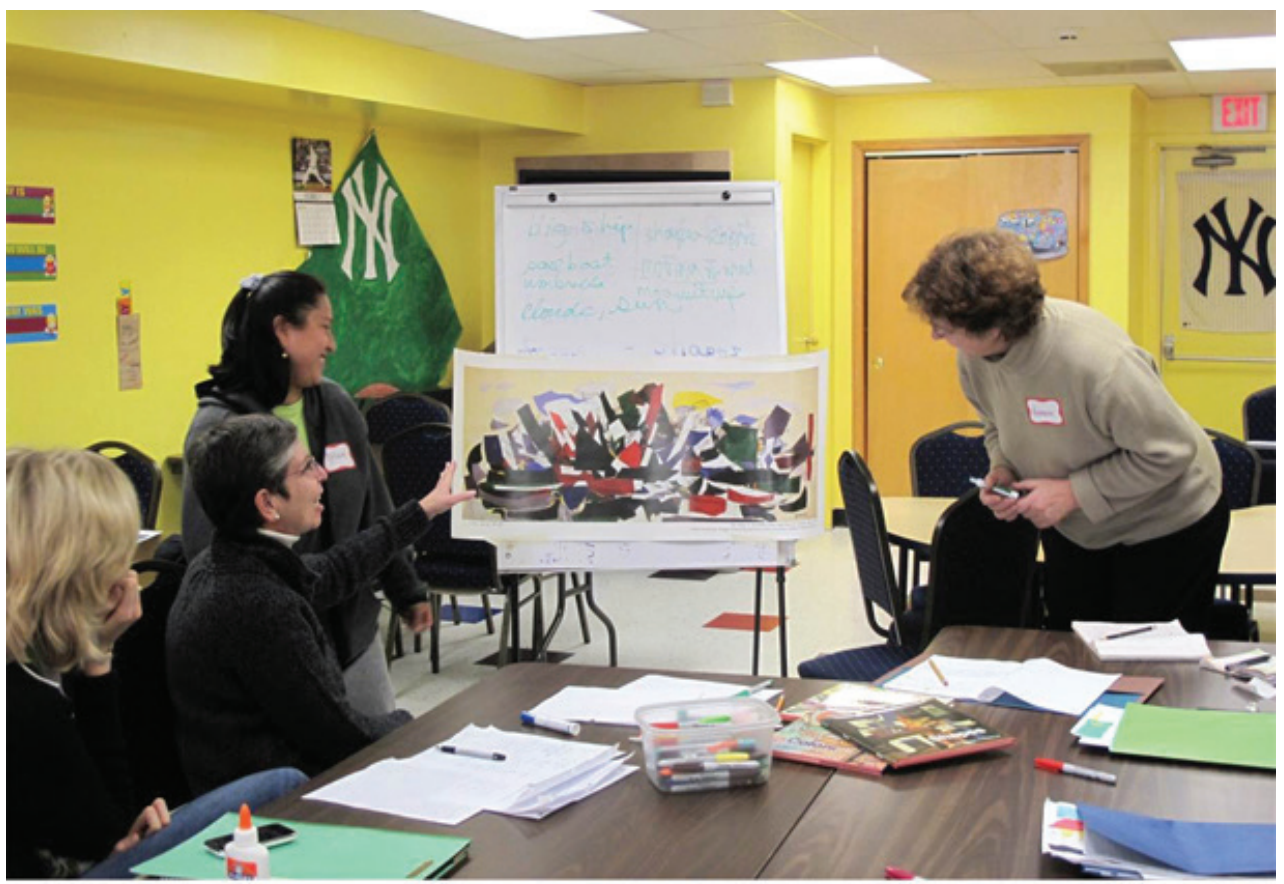

Fig 3. Parent Sessions: Within a peer group context, parents share their observations and diverse interpretations of an abstract work. The use of VTS invites and values the participants' thoughts and background knowledge and is intrinsically an empowering pedagogy for viewers new to art. 


\section{VTS and Social Inclusion}

VTS methodology served to support the children's language development and observation skills, but it also served to promote social inclusion for parents. During parent-only sessions, AJ/AT educators introduced the VTS methodology in order to empower parents to view and share their observations drawing from their personal experiences and knowledge, despite limited English language skills or experience with art and museums. The methodology has been recently employed with adult English Language Learners (ELLs) by CALTA21, an initiative funded by a National Leadership Grant from the Institute of Museum and Library Services that aims at bridging adult ELLs and museums. Here, adult literacy instructors used VTS' open-ended questions in the classroom while exploring selected works of art, with participants ultimately using them to facilitate their own discussions in the museum space. While the primary aim for CALTA21 was language acquisition, Patricia Lannes, CALTA21 Project Director, observed that:

These exchanges empower participants by validating their own cultures, stories, and experiences, while simultaneously validating the cultures of other participants and of their newly adopted community. In other words, the experience of participating in these discussions is empowering and engaging not because it bequeaths the participants with some essential knowledge that they previous lacked but rather because it demonstrates the value of communicating one's own opinions, stories, and experiences. (http://incluseum.com/2013/05/23/calta21-a-model-for-bridgingmuseums-and-immigrant-english-learners/.)

Educators used works of art and materials throughout the program that reflected the participants' cultures and made connections to their experiences, echoing research that demonstrated participants' desire to see themselves and their families, as Latinos, reflected and included in the museum (Stein, Garibay and Wilson 2008: 187). Understanding the value of using the participants' home language, the museum recruited a bilingual/bicultural educator to facilitate the program in English and Spanish, and written materials were bilingual (Sandell, 2003: 56; Stein, Garibay and Wilson 2008: 187). These efforts led to a deepened sense of engagement and meaning-making reflected in the parents' eagerness to make connections between their personal experiences and their experiences in the program.

Visits to the KMA for AJ/AT sessions offered children and their families an objectrich, multi-sensory, experiential, and social environment that encouraged questions and conversation, developed print and word awareness, and gave words meaning and context. Parents' perceptions of their children's learning changed as a result of observing their inquirybased discussions in the classroom and museum contexts, and they repeatedly expressed enthusiasm for their children's progress. Parents linked school readiness and social inclusion as they spoke of two discoveries resulting from sharing in inquiry-based discussions: specific activities they could utilize to support their children's learning and insights they garnered about their experiences as new immigrants. Their optimism was reminiscent of Ellis and Dunckel's (2010: 114) 'cascading effects' on parental involvement that result from gratifying experiences relating to their children's learning.

Informal Learning in Museums and the Role of the Parents

Art museums represent unique opportunities for learning which include access to content-rich exhibitions; immersive experiences with art and art making; and experiences with real artifacts and original works of art. Museums are places where families with young children 'construct meaning, have genuine choices, encounter challenging tasks, take control over their own learning, collaborate with others, and feel positive about their efforts' (Paris, Yambor \& Packard 1998: 271). Young children develop background knowledge on a variety of topics through informal learning experiences in museums and elsewhere, often prompted by their own or their parents' interests, long before they are introduced to science, history or social studies in school (Crowley and Jacobs 2011: 334-37). While museums offer opportunities for free-choice learning, parents play an important role in mediating young children's learning experiences in museums, and by making connections to past events, individual experiences and related content in conversations that take place during and after the visit (Borun, M. 2002: 253; Falk and Dierking, 2000:93-94). 


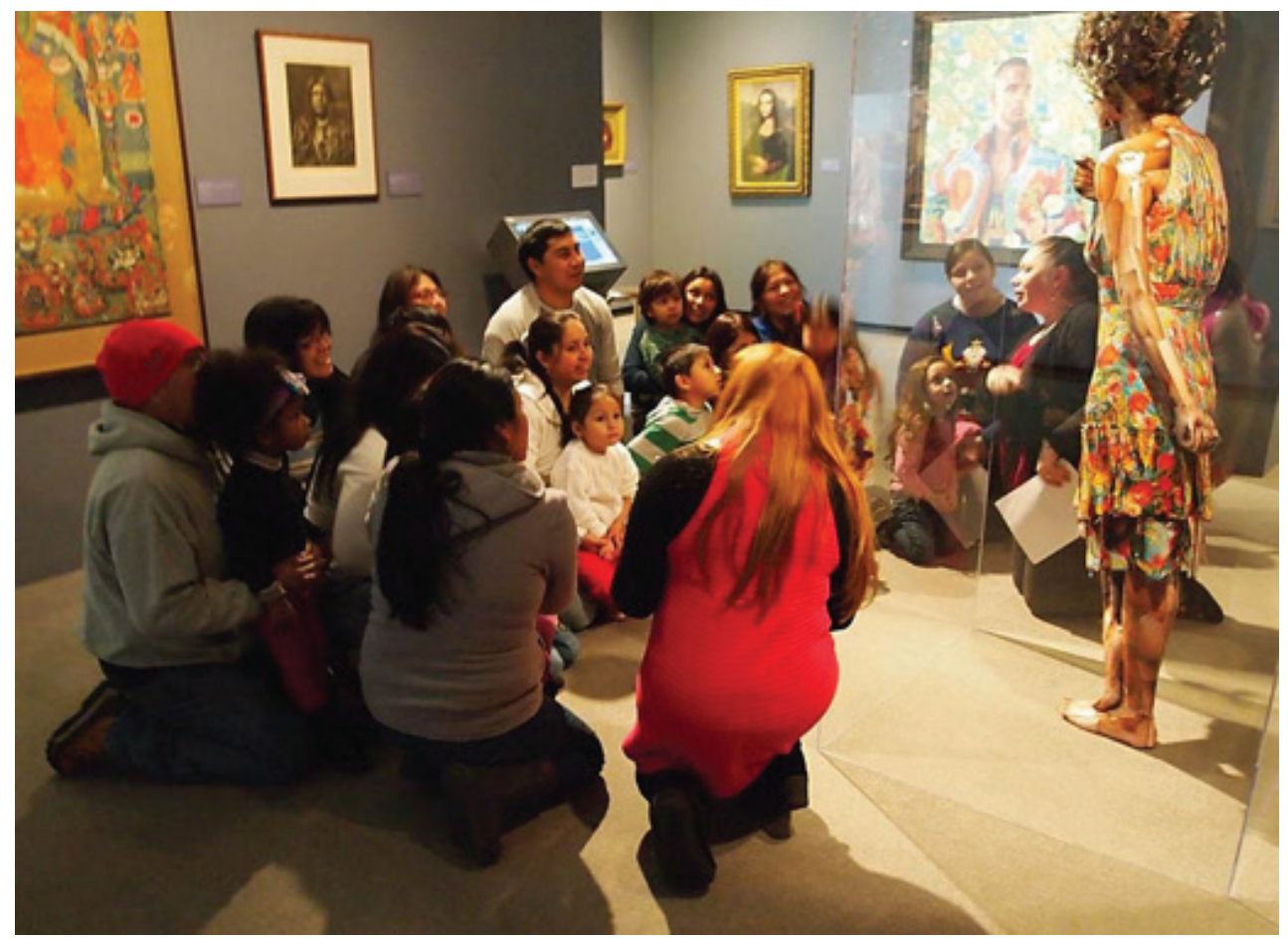

Fig 4. Parent and child museum visit: A Museum educator facilitates thoughtful looking and discussion with parents and children, using an openended inquiry model.

Parents need to feel welcome in museums and empowered to lead conversations and activities with their children. Yet, the majority of AJ/AT parents had never visited a museum before. As recent immigrants, they may have had different perceptions of learning and museums, based on experiences in their home countries in addition to their experiences in the United States (Stein, Garibay and Wilson 2008: 184-85). To support a successful first visit, the AJ/ AT families needed additional support - from physically getting to the museum to navigating exhibits. The AJ/AT program increased participants' museum literacy, defined as the comfort and confidence with which individuals approach museums, and augmented the potential of authentic engagement with art and art making, experienced within a trusting environment, as being 'an instrument for psycho-social inclusion' (Fernandez-Cao 2010: 401-404). The AJ/ AT curriculum included multiple opportunities for families to explore the museum, each time making the space a more accessible resource for learning and enjoyment, and thus moving the participants from novice visitors to museum literate visitors familiar with the KMA and its offerings. This was accomplished by preparing parents with the 'tools' for arts participation and designing the museum visits' activities to progressively engage families in more independent exploration. Research shows how multiple visits to the museum build a sense of comfort and increase learning opportunities for community members in the museum (Hein 2001: 34, Melber 2006: 39).

\section{Parent Reflections}

In the 2012-2013 academic year, the Arte Juntos/Art Together collaboration between FS/PP and KMA involved 60 children and their families. At the culminating event, parents were asked to share their reflections on how they were impacted by the program. Since these conversations were conducted in Spanish, translations of the parents' comments are included below.

Parents were asked to share their feedback on their comfort level visiting the museum. A participant said: 'A museum can be intimidating, overwhelming. But seeing now that it [museums] 
can be accessible has made me feel more encouraged to go.' When asked how AJ/AT had changed what participants could do in a museum, parents responded positively. One parent said, 'Now I would probably see myself going to a place like the MET. Because I don't know that much about art, now I know how to ask questions and to look.'

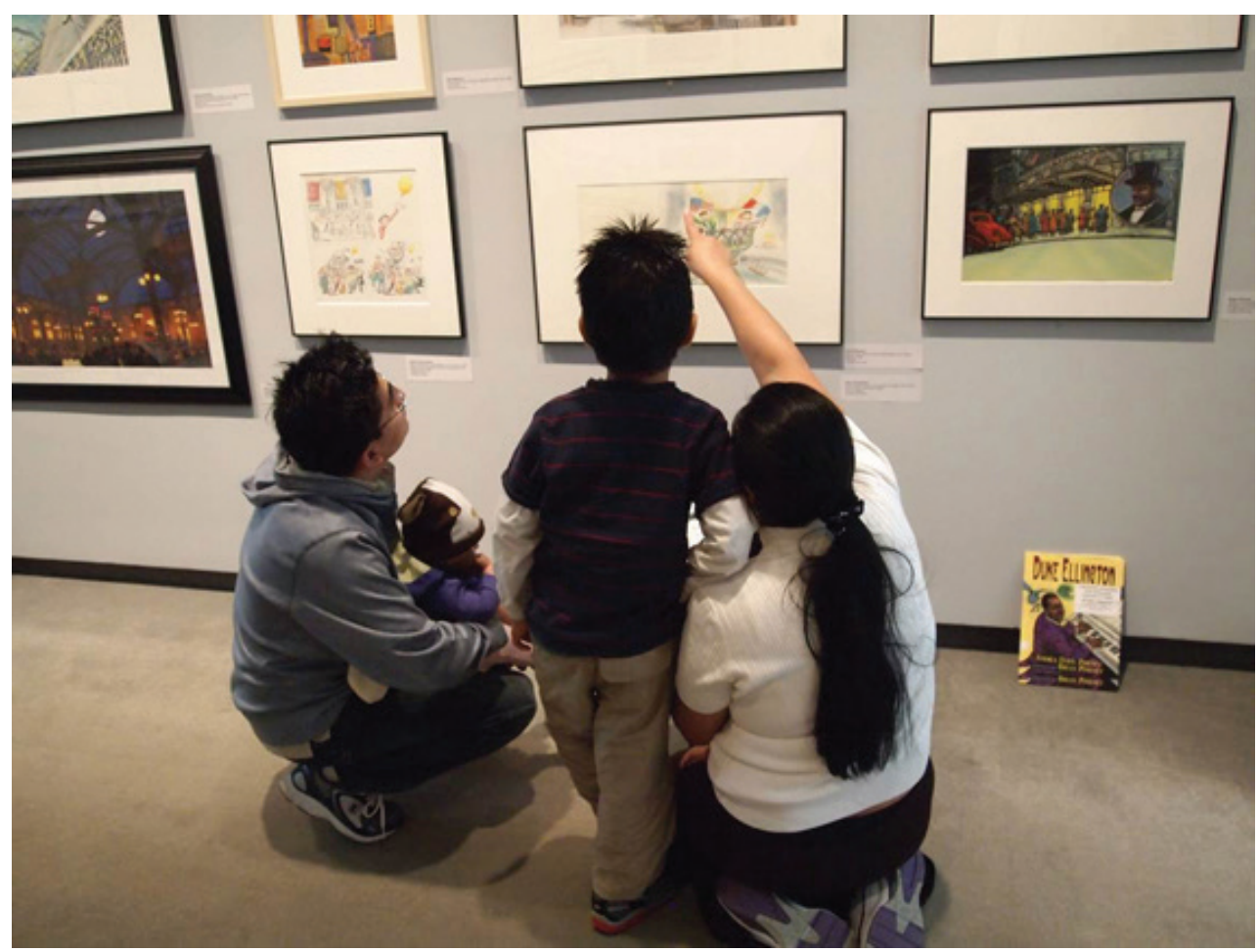

Fig 5. Provided with a bilingual Family Guide, a family with their Pre-K son independently explore KMA's galleries and search for elements in a painting.

In particular, parents were asked to reflect on what they thought about their role in promoting school readiness. One parent responded:

In my country, it is the custom that the kids don't get exposed to using crayons and scissors until they are older - four or five years old. Now I understand the earlier they get used to playing with materials, the better.

Another parent reported: 'I learned about talking with the kids, listening, and asking them questions. I have seen a change in the kinds of conversations we have.' Another stated that after participating she had 'a better idea of how to do the activities, we now know the steps.' One parent recognized that the program offered 'a more fun way to learn, playing, using different colors, rather than the more rote way to learn. In my country, they learn by repetition.' Another parent noted that 'the program gave us many more ways to play and work with our kids' and that 'I see that now they are focused, they notice the details, this is fun for them, but they are also developing skills.'

These comments hearken back to the goals of enhancing school readiness. Introducing materials to very young children for activities such as drawing and inventive writing are part of the early enrichment that builds emergent literacy skills. Exposure to the child's first language during these activities is linked to sustained gains in skills such as concepts of print (Coppola 2005:21), another vital element in school readiness. Likewise, increased conversations, as the parent describes, are critical to developing vocabulary. Perhaps more than any other skill, strong vocabulary supports school readiness and eventual achievement (Biemiller 2006: 41-51). 


\section{Conclusion}

The Arte Juntos/Art Together and First Steps/Primeros Pasos collaboration represents combined efforts to stimulate school readiness in a linguistically diverse suburban community. The inquiry-based approaches, including VTS, served dual purposes - promoting school readiness and social inclusion for Latinos in that community. The family programming brought about by AJ/AT and FS/PP demonstrates the efficacy of museum-school collaborations that remain responsive to the needs of families and young children. As more research and innovation is needed to support school readiness and social inclusion in diverse communities, programs such as Arte Juntos/Art Together can serve as a model for collaborations between museums/ cultural institutions and early childhood centers.

Parent comments clearly relate to the goals of the collaboration in providing and structuring enriching experiences for young children that prepare them for school. These comments point to a transformative experience with social inclusion that fuels their willingness and comfort to access museums independently. The design of the AJ/AT curriculum organizes preparatory experiences for children that prove to be highly gratifying; they engage children and parents in authentic experiences and empower them to make meaning of their learning, and then promote the language and vocabulary that supports self-expression. These are the ideal experiences in early childhood that build strong school readiness. As children demonstrate their delight and growing competence in these activities, parents gain both the confidence and deep appreciation for their role in preparing their children for school.

Received: 11 October 2014

Finally accepted: 6 March 2015

\section{Acknowledgements}

We would like to acknowledge the work of the First Steps/Primeros Pasos educators for their tireless efforts to make conditions better for Rivertown's young children. This work would not be possible without the continued support of multiple funders and the Rivertown schools.

\section{Notes}

1 The US Census uses the terms 'Hispanic' and 'Latino' interchangeably to refer to individuals of any race from 'Mexican, Puerto Rican, Cuban, Central or South American, or some other Hispanic origin.' This study uses the terms interchangeably as well.

2 DeSantis, K., Housen, A., (2007), 'Highlights of Findings-San Diego:Aesthetic development and creative and critical thinking skills study', Visual Understanding in Education http:// www.issuelab.org/resource/aesthetic development and creative and critical thinking skills study, accessed 29 March 2015.

\section{References}

Ackerman, D. J., \& Tazi, Z., (2015), Enhancing young Hispanic dual language learners' achievement: Exploring strategies and addressing challenges, (Policy Information Report, ETS Research Report No. RR-15-01), Princeton, NJ: Educational Testing Service, http://dx.doi.org/10.1002/ets2.12045.

Berube, A. (2011), The state of metropolitan America: Suburbs and the 2010 Census, Speech presented at the State of Metropolitan America: Suburbs and the 2010 Census Annual Conference. Arlington, VA, http://www.brookings.edu/research/ speeches/2011/07/14-census-suburbs-berube.

Biemiller, A., (2006), 'Vocabulary development and instruction: A prerequisite for school learning,' in D.K. Dickinson and Susan B. Neuman (eds.), Handbook of Early Literacy Research, Volume 2, 41-51, New York, London: The Guilford Press. 
Borun, M., (2002), 'Object-based learning and family groups,' in S. Paris (ed), Perspectives on Object-Centered Learning in Museum, 245-60, London: Lawrence Erlbaum Associates, Inc.

Bowers, B., (2012), 'A look at early childhood programming in museums,' Journal of Museum Education, 37 (1) 39-48.

Children's Defense Fund, (2011) State of America's Children 2011, http://www. childrensdefense.org/child-research-data-publications/data/state-of-americas-2011. pdf.

Coppola, J., (2005), 'English language learners: Language and literacy development during the preschool years', The New England Reading Association Journal, Vol. 41 (2), 18-23.

Crowley, K. and Jacobs, M., (2011), 'Building islands of expertise in everyday family activity,' in G. Leinhardt, K. Crowley \& K. Knutson (eds), Learning conversations in museums, 333-356, Mahwah, New Jersey: Erlbaum Associates.

Downey, S., Krantz, A., and Skidmore, E., (2010), 'The Parental Role in Children's Museums: Perceptions, Attitudes, and Behaviors', Museums and Social Issues, $A$ Journal of Reflective Discourse, 5 (1) 15-34.

Ellis, S., Dunckel, B.A., (2010), 'Creating opportunities through classroom-based early childhood science', Museums \& Social Issues, 5(1) 103-116.

Falk, John H. and Dierking, L., (2000), Learning from Museums: Visitor Experiences and the Making of Meaning, Walnut Creek, CA: AltaMira Press. (2002), Lessons Without Limit: How Free-Choice Learning is Transforming Education, Walnut Creek, CA: AltaMira Press.

Farrell, B., Medvedeva, M., (2010), 'Demographic transformation and the future of Museums', American Association of Museums, http://culturalpolicy.uchicago.edu/ publications/Demographic-Transformation.pdf.

Fernández-Cao, M.L., del Río Diéguez, M., Iribas Rudín, A.E., García Lledó, G., Mollá Giner, M., Rigo Vanrell, C., Romero Rodriguéz, J., Dominguéz Rigo, M., Navajas Seco, R., (2010), 'Social functions of art: Educational, clinical, social and cultural settings. Trying a new methodology', International Journal of Education through Art, 6(3) 397-412.

Flanagan, K. D., and McPhee, C., (2009), The children born in 2001 at kindergarten entry: First findings from the Kindergarten Data Collections of the Early Childhood Longitudinal Study, Birth Cohort (ECLS-B) (NCES 2010-005), Washington, DC: National Center for Education Statistics, Institute of Education Sciences, U.S. Department of Education.

García, E., Jensen, B., (2009), 'Social Policy Report: Early educational opportunities for children of Hispanic origins', Society for Research in Child Development, 23(2)3-19.

Hart, B., Risley, T.R., (1995), Meaningful differences in the everyday experience of young American children, Baltimore: Paul H. Brookes Publishing Company, Inc.

Hein, George E., (2001), Learning in the Museum, New York: Routledge.

Housen, A., (1983), The eye of the beholder: Measuring aesthetic development. Ph.D. Thesis: Harvard University. 
Housen, A. (2001) 'Aesthetic thought, critical thinking and transfer,' Arts and Learning Research Journal (18) 99-131.

Housen, A., and Yenawine, P., (2000), Visual Thinking Strategies basic manual grades K-2. New York: Visual Understanding in Education.

The Incluseum. (2013) 'CALTA21: A Model for Bridging Museums and Immigrant English Learners', http://incluseum.com/2013/05/23/calta21-a-model-for-bridgingmuseums-and-immigrant-english-learners/

Janus, M., Duku, E., (2007), 'The school entry gap: Socioeconomic, family, and health factors associated with children's school readiness to learn', Early Education and Development, 18(3) 375-403.

Lee, V.E., Burkham, D.T., (2002), Inequality at the starting gate, Executive Summary. Washing DC: Economic Policy Institute, epsl.asu.edu/epru/articles/EPRU-0603-138OWl.pdf

Luke, J.J., McCreedy, D., (2010), 'Making parent involvement a community issue,' Museums \& Social Issues, 5(1) 5-14.

Magnuson, K., Waldfogel, J., (2005), 'Early childhood care and education: Effects on ethnic and racial gaps in school readiness,' The Future of Children, 15(1) 169-196.

Melber, L. M., (2006), 'Learning in unexpected places: Empowering Latino parents', Multicultural Education, 13 (4), 36-40.

Neuman, M., Bennet, J., (2001), 'Starting Strong: Policy implications for early child education and care in the US', Phi Delta Kappan, 83(3) 246-254.

Neuman, S., (2003), 'From Rhetoric to Reality: The Case for High Quality Compensatory Pre-Kindergarten programs', Phi Delta Kappan, 85(4), 284-291.

Paris, S., Yambor, K., \& Packard, B., (1998), 'Hands-on biology: A museum-schooluniversity partnership for enhancing students interest and learning in science,' The Elementary School Journal, 98(3), 267-88.

Peña, D.C., (2000), 'Parent involvement: Influencing factors and implications,' The Journal of Educational Research, 94(1) 42-54.

Sandell, R., (2003), 'Social inclusion, the museum and the dynamics of sectoral change', Museum and Society 1, 45-2.

Silverman, L., (2002), 'The Therapeutic Potential of Museums as Pathways to Inclusion', in R. Sandell (ed) Museums, Society and Inequality, 69-83, London and New York: Routledge.

Snow, K., (2007), 'Integrative views of the domains of child function: Unifying school readiness,' in Robert C. Pianta, Martha J. Cox and Kyle L. Snow (eds) School readiness and the transition to Kindergarten in the era of accountability, 197-216, Baltimore: Paul H Brookes Publishing.

Swick, K., (2009), 'Promoting school and life success through early childhood family literacy', Early Childhood Education Journal (36) 403-6.

Suro, R., Singer, A., (2002), 'Latino growth in metropolitan America: Changing patterns, new locations', Washington DC: The Brookings Institution. http://www.brookings.edu/ research/reports/2002/07/demographics-suro. 
Tazi, Z., (2010), 'Preventing the gap in preschool: A suburban community model,' in Andrea Honigsfeld and Audrey Cohan (eds), Breaking the mold of school instruction and organization: Innovative and successful practices for the twenty-first century, 174180, United Kingdom: Rowman and Littlefield.

Whitescarver, K. and Cossentino, J., (2011), 'What do you see that makes you say that? Visual thinking in Montessori environments', Montessori International (April-June) 20-1, http://www.vtshome.org/system/resources/0000/0241/VTS-Montessori International.pdf.

Wickens, K. Allison., (2012), 'Museums and community: The benefits of working together', Journal of Museum Education, 37(1) 91-100.

\title{
Authors
}

\section{*Zoila Tazi, PhD \\ Mercy College}

Dr. Tazi has over 25 years of experience working with children and families. She has been in an administrative capacity in several children's programs as director of a Head Start program, a family literacy program and as a School Principal. Dr. Tazi is a frequent conference presenter on issues relating to the education of bilingual and immigrant children. Currently Dr. Tazi is Associate Professor in the Educational Leadership Department at Mercy College. Her research examines bilingualism in early childhood, school readiness and early childhood education.

Zoila Tazi, $\mathrm{PhD}$

Associate Professor

Educational Leadership Department

MERCY COLLEGE

555 Broadway

Dobbs Ferry, NY 10522

ztazi@mercy.edu

\author{
${ }^{* *}$ Helena Vidal \\ Katonah Museum of Art \\ Helena Vidal \\ Project Manager, Arte Juntos/Art Together \\ KATONAH MUSEUM OF ART \\ 134 Jay Street \\ Katonah, NY 10536 \\ hsvidal@verizon.net
}

Helena Vidal manages, collaboratively develops and facilitates KMA's Arte Juntos/Art Together program, which serves immigrant families in Westchester, NY. As a consultant and independently contracted museum educator, Ms. Vidal brings valuable years of museum experience to her work that supports KMA's community engagement. Previously, she was Project Director for El Museo del Barrio's Permanent Collection Online, where she oversaw the development of curricula and interpretive materials. Her past professional positions include Director of Education and Public Programs, El Museo del Barrio, Assistant Director of Education, Whitney Museum of American Art, and Associate Director of Student Programming, New York University. 


\section{***Karen Rattazzi-Stein, MPS, ATR}

Katonah Museum of Art

Karen Rattazzi-Stein is the Director of Education at the Katonah Museum of Art (KMA), Katonah, NY. Her thirty-five years of teaching and administrative experience has been dedicated to and advocating for learning through art. In 2005, Ms. Stein expanded KMA's mission to enrich and support the literacy and social inclusion needs of the growing Latino immigrant community, with a focus on young families. Ms. Stein presents KMA's work at state and national conferences and consults with museum educators on community engagement initiatives. She holds a Master Degree in Art Therapy and Creativity Development from the Pratt Institute, NY.

\section{Karen Stein}

KATONAH MUSEUM OF ART

Director of Education

134 Jay Street

Katonah, NY 10536

kstein@katonahmuseum.org

Katonah Museum of Art

134 Jay Street

Katonah, NY 10536

www.katonahmuseum.org

www.ArteJuntosArtTogether.com

Website for the program presented in the article.

Primary telephone contact: Karen R. Stein 914-232-9555 Katonah Museum of Art Fax number: 914-232-3128 